\title{
In Vitro Quality Evaluation of Amoxicillin Trihydrate Capsules Marketed in Gaza Strip-Palestine
}

\author{
Nahed Diab HEGAZY* \\ College of Medicine and Health Science, Department of Pharmacy and Biotechnology, University of Palestine, Gaza Strip, \\ Palestine
}

\begin{abstract}
The objective of this Post-Marketing Pharmaceutical Quality Evaluation of Amoxicillin trihydrate 500mg capsules to evaluate the quality standards of seven different marketed brands with various price ranges, collected from retail drug stores of Gaza-strip, Palestine. The quality of amoxicillin trihydrate capsules was assessed through evaluation of identification, uniformity of weight, disintegration, dissolution and assay of content of active ingredient using spectrophotometric method. It was observed that six of seven brands of amoxicillin trihydrate capsules meet quality specifications in Pharmacopoeia. The spectrophotometric method which used in assay of content of active ingredient of amoxicillin trihydrate capsules is simple, inexpensive, easy to use and could be used in routine monitoring especially in the absence of high technology equipment. This study shows the needing for more market monitoring of all available brands of all drugs in the drug market of Gaza Strip-Palestine.
\end{abstract}

Keywords: Amoxicillin trihydrate, pharmaceutical quality evaluation, dissolution test, gaza strip, pharmacopoeial specifications.

\section{INTRODUCTION}

Currently, it is estimated that $10-15 \%$ of the global drugs supplied are counterfeit. The prevalence is higher in developing countries, in Africa, and in parts of Asia and Latin America where up to 30-60\% of drugs on the market are counterfeit. Among the medicines, antibiotics account for $28 \%$ of global counterfeit medicines. These problems have resulted in a weak therapeutic efficiency and devel-

${ }^{*}$ Corresponding author:

E mail: n.hegazy@up.edu.ps

Tel: +972599171907

ORCID:

https://orcid.org/0000-0002-1207-3325

(Received 26 February 2021, Accepted 7 June 2021) 
opment of dire resistant strains. There is, therefore, a need to routinely assess the pharmaceutical quality of drugs ${ }^{1}$. Amoxicillin is an oral semi-synthetic, B-lactam antibiotic used to treat bacterial infections caused by susceptible microorganisms. It is usually the drug of choice within the class because it is better absorbed, following oral administration, then other $\beta$-lactam antibiotics ${ }^{2}$. Amoxicillin (500 mg capsules or tablets) is categorized as a biopharmaceutics classification system (BCS) class 1 drug. A recently published biowaiver monograph on amoxicillin trihydrate recommends submission of either comparative in vitro dissolution data or in vivo bioequivalence data as evidence to establish therapeutic equivalence of generic solid oral amoxicillin products of 250 and $500 \mathrm{mg}^{3}$.

Post-Marketing monitoring of medicines has been performed to evaluate the quality of marketed pharmaceutical brands ${ }^{4}$. Quality of the drug according to the modern definition requires that the product contain the quantity of each active ingredient claimed on its label within the applicable limits of its specifications, contain the same quantity of active ingredient from one dosage unit to the next, be free from extraneous substances, maintain its potency, therapeutic availability and appearance until used, and upon administration release active ingredient for full biological availability ${ }^{5}$. Quality control is the part of Good Manufacture Practice (GMP) that is concerned with sampling, specifications, testing, documentation and release procedures which ensure that the necessary and relevant tests are actually carried out and that the materials are not released for use, not products released for sale or supply, until their quality has been judged to be satisfactory ${ }^{6}$. The safety and efficacy of a pharmaceutical dosage form can be guaranteed when its quality is reliable. The efficacy of pharmaceutical dosage forms generally depends on their formulation properties, and manufacturing methods, hence it is likely that the quality of dosage form may vary .

The increase in the number of generic drug products from different multiple sources has placed people and prescribers in a position of selecting one from among several seemingly equivalent products ${ }^{8}$. Many of these products are inexpensive and affordable, but with uncertainly about their quality ${ }^{9}$. Several studies showed that switching from branded to generic medicine might result in changes of pharmacokinetics/pharmacodynamics profile, leading to subtherapeutic concentration or therapeutic failure and or adverse reactions ${ }^{10}$. It is very essential to do bioequivalence studies for generic products on account of any significant difference in the rate and extent by which the therapeutic ingredients become available at the site of drug action, administered under uniform conditions in an adequately designed study ${ }^{11}$. To identify bioavailability prob- 
lems dissolution testing serves as an indicator ${ }^{12}$. Biopharmaceutically as well as chemically equivalent drug products must have the same quality, strength, purity, content uniformity, disintegration and dissolution rates ${ }^{13}$. In vitro quality control (QC) of pharmaceutical products is a fixed set of investigation started during production by in-process quality control tests and after production by finished product quality control tests as per official pharmacopoeias and different regulatory agencies. QC tests help in avoiding the confusion regarding safety, potency, efficacy and stability of pharmaceuticals ${ }^{14}$.

Regular control of drug products has long been an integral part of the pre-and post-marketing quality control to safeguard the public. Many developing countries do not have an effective means of monitoring the quality of generic drug products in the market. This results in a widespread distribution of substandard and/or counterfeit drug products ${ }^{8}$.

There are a number of cases related to substandard and counterfeit drugs. Composition and ingredients of substandard drugs don't meet the correct scientific specifications for these reasons they are ineffective and often dangerous to the patient. Counterfeit drugs may include products with the correct ingredients but fake packaging, with the wrong ingredients, without active ingredients or with insufficient active ingredients ${ }^{15}$. Substandard and counterfeit drugs are a major cause of morbidity, mortality and loss of public confidence in drugs and health structures ${ }^{16}$. WHO has estimated that approximately $10 \%$ of the global pharmaceuticals market consists of counterfeit drugs, but this estimate increases to $25 \%$ in developing countries, and may exceed $50 \%$ in certain countries. FDA estimates that up to $25 \%$ of the drugs consumed in poor countries are substandard or counterfeit ${ }^{15}$. Substandard and counterfeit drugs are not only limited to poor and developing countries but also intensely noticeable in developed countries. In 2007-2008, due to the uses of adulterated blood thinner, heparin 149 Americans were dying that was legally imported. In 2012, contaminated steroids killed 11 people and sickened another 100 people in the US. In another case, vials of the cancer medicine, Avastin were found to contain no active ingredients ${ }^{17}$. In a study of WHO found that $28 \%$ of antibiotic and $20-90 \%$ of antimalarial drugs were failed quality specifications ${ }^{18}$.

As amoxicillin is widely used antibiotic in Gaza Strip, the objective of this study was to assess the quality of different leading brands of amoxicillin trihydrate 50omg capsules formulation commercially available in the market of Gaza Strip. This study also used and validated an analytical method for the assay of content of amoxicillin trihydrate in the capsules, which will be easy to use, accurate, simple and inexpensive when compared with other methods. 


\section{METHODOLOGY}

\section{Materials}

Amoxicillin trihydrate (Merck, Germany), Amoxicillin trihydrate capsules (500 mg): seven brands, Sodium hydroxide, Hydrochloric acid, Ferric sulphate (Merck, Germany).

\section{Instruments}

Analytical balance (YMC, Japan), Disintegration apparatus (Toyama sangyo, Japan), Dissolution test apparatus (Apparatus II "Paddle apparatus"), Electricheating distilling apparatus, Magnetic stirrer (Heidolph, Germany), Micrometer (Mitutoyo, Japan), Micropipette (Nichiryo, Japan), UV-visible spectrophotometer (equipped with 1cm Shimadzu, 1601, matched quartz cells).

\section{Methods}

\section{Identification test of active substance}

\section{Amoxicillin trihydrate capsules}

20 capsules from each brand were weighed. A quantity of the powder from each brand containing $0.05 \mathrm{~g}$ of amoxicillin trihydrate was weighed, then $10 \mathrm{ml}$ of $1 \%$ ferric sulphate was added ${ }^{19}$.

\section{Amoxicillin trihydrate pure powder}

A $0.05 \mathrm{~g}$ of amoxicillin trihydrate pure powder was weighed, then $10 \mathrm{ml}$ of $1 \%$ ferric sulphate was added.

\section{Uniformity of weight determination}

20 capsules from each brand were taken at random and brushed from dust using soft brush then were weighed individually using analytical balance. Each capsule was opened without losing any part of the shell and the contents was removed as completely as possible then the shell was weighed. The weight of the content is the difference between weighing's (weight of capsule "content \& shell" - weight of shell). The average weight of content, percentage deviation from the average weight and SD were calculated (BP 2018).

\section{Disintegration test}

Disintegration time of six units per brand was determined in distilled water at $37 \pm 1^{\circ} \mathrm{C}$ using disintegration apparatus (BP 2018). Determination was done in triplicate, and then the mean and SD were calculated. 


\section{Dissolution test}

According to official monograph, the dissolution was performed according USP 41 NF20. The dissolution rate was determined by using dissolution apparatus II, and $900 \mathrm{ml}$ of distilled water. Six units were used from each brand. The dissolution medium was maintained at $37 \pm 0.5^{\circ} \mathrm{C}$, and the paddle was rotated at $75 \mathrm{rpm}$. Samples (10 ml) were withdrawn at different time intervals (10, 20, 30, 45, and 60 minutes). The samples were filtered and diluted appropriately with distilled water. The absorbance was measured using UV-visible spectrophotometer at $272 \mathrm{~nm}$. The content of amoxicillin trihydrate capsules in each sample was determined based on the calibration curve and regression equation which was generated according to the following procedure:

- Accurately $100 \mathrm{mg}$ of pure amoxicillin trihydrate powder was dissolved in distilled water and diluted with distilled water to the mark in a $50 \mathrm{ml}$ volumetric flask.

- The resulting solution was filtered then different volumes were taken ( $1 \mathrm{ml}, 2$ $\mathrm{ml}, 3 \mathrm{ml}, 4 \mathrm{ml}$ and $5 \mathrm{ml}$ ) using pipette and dilution was done with the distilled water to the mark $50 \mathrm{ml}$ volumetric flask.

- Different aliquots of standard solutions $(40 \mu \mathrm{g} / \mathrm{ml}, 80 \mu \mathrm{g} / \mathrm{ml}, 120 \mu \mathrm{g} / \mathrm{ml}, 160$ $\mu \mathrm{g} / \mathrm{ml}$ and $200 \mu \mathrm{g} / \mathrm{ml}$ ) were prepared.

- The absorbance of the resulting solutions was measured at the maximum 272 nm using UV-visible spectrophotometer.

- Procedure was done in triplicate, and the mean of the absorbance values was calculated.

A linear plot with concentration of amoxicillin trihydrate on $\mathrm{X}$-axis and absorbance on Y-axis, and the regression equation were obtained using Microsoft excel. The dissolution profiles of the different brands of amoxicillin trihydrate capsules were generated from the graph of the percentage amount of the dissolved drug versus time.

\section{Analytical method validation}

The quantitative determination method for amoxicillin trihydrate in the capsules was validated through assessment of accuracy and precision. The accuracy and precision of the methods were assessed by performing recovery experiments. Recovery experiment was performed as following: to a fixed amount of drug in the dosage form (pre-analyzed), pure drug was added at three amount levels (each added amount was performed in triplicate), then total amount was found by Dibbern et al. method and \% recovery of pure drug was calculated ${ }^{20}$. 
The detailed procedures were done as the following:

Standard preparing: A quantity of pure powder containing $22.5 \mathrm{mg}$ of amoxicillin trihydrate was added to $50 \mathrm{ml}$ volumetric flask then 0.1 M sodium hydroxide was added till reach the mark and shaken. The resulting solution (a) was filtered and $1 \mathrm{ml}$ of the filtrate was diluted to $100 \mathrm{ml}$ with $0.1 \mathrm{M}$ sodium hydroxide to get solution (b) with concentration of $4.5 \mu \mathrm{g} / \mathrm{ml}$ of amoxicillin. The absorbance of the solution (b) was measured at the maximum at $247 \mathrm{~nm}$ using UV-visible spectrophotometer. The content was calculated taking 286 as the value of A $(1 \%, 1 \mathrm{~cm})$. Volumes that contain $(10 \mu \mathrm{g}$, $20 \mu \mathrm{g}$ and $40 \mu \mathrm{g}$ ) were taken from the solution (b).

Sample preparing: 20 capsules were taken, the contents was removed as completely as possible and weighed accurately. A quantity of the powder from capsules containing $22.5 \mathrm{mg}$ of amoxicillin trihydrate was added to $50 \mathrm{ml}$ volumetric flask then 0.1 M sodium hydroxide was added till reach the mark and shaken. The resulting solution (c) was filtered and $1 \mathrm{ml}$ of the filtrate was diluted to $50 \mathrm{ml}$ with $0.1 \mathrm{M}$ sodium hydroxide to get solution (d) with concentration of $9 \mu \mathrm{g} / \mathrm{ml}$ of amoxicillin. Suitable dilution was made to get solution (e) with concentration of $1.5 \mu \mathrm{g} / \mathrm{m}$ of amoxicillin. The absorbance of the solution (e) was measured at the maximum at $247 \mathrm{~nm}$ using UV-visible spectrophotometer. The content was calculated taking 286 as the value of A $(1 \%, 1 \mathrm{~cm})$. Volume that contain $20 \mu \mathrm{g}$ of drug was taken from solution (e).

\section{Recovery experiment}

After preparing the solutions of pure drug and sample of amoxicillin trihydrate the following steps were done for recovery:

- Each volume that contains $(10 \mu \mathrm{g}, 20 \mu \mathrm{g}$ and $40 \mu \mathrm{g})$ of pure drug was taken and added to volume of sample containing $20 \mu \mathrm{g}$.

- The absorbance of the resulting solutions were measured using UV-visible spectrophotometer at the maximum at $247 \mathrm{~nm}$.

- The total amount was calculated taking the value of A (1\%, $1 \mathrm{~cm}$.) as 286 for amoxicillin trihydrate.

- The percentage recovery of pure drug was calculated as the following:

\section{\% recovery = total amount (pure drug \& sample) - amount of sam- ple/ amount of pure drug $x 100$}

- Each added amount of pure drug to the sample was performed in triplicate.

- The mean, SD and Relative Standard Deviation \% (RSD \%) were calculated. 


\section{Assay of content of active ingredient}

\section{Application of validated method}

20 capsules were taken, the contents was removed as completely as possible and weighed accurately. A quantity of the powder containing $22.5 \mathrm{mg}$ of amoxicillin trihydrate was added to $50 \mathrm{ml}$ volumetric flask then $0.1 \mathrm{M}$ sodium hydroxide was added till reach the mark and shaken. The resulting solution was filtered and $1 \mathrm{ml}$ of the filtrate was diluted to $50 \mathrm{ml}$ with $0.1 \mathrm{M}$ sodium hydroxide. The absorbance of the resulting solution was measured at the maximum at $247 \mathrm{~nm}$ using UV-visible spectrophotometer. The content was calculated taking 286 as the value of $\mathrm{A}(1 \%, 1 \mathrm{~cm})^{21}$. Determination was done in triplicate, and then the mean of percentage content and SD were calculated.

\section{RESULTS AND DISCUSSION}

\section{Identification test of amoxicillin trihydrate}

The identification test of the standard (pure amoxicillin trihydrate) and the various brands resulted as intense yellow color was produced in standard as well as in all brands. From the results it was observed that all brands contain the needed active substance by comparing the result with that of standard pure active substance.

The results of the physicochemical properties of the various brands of amoxicillin trihydrate capsules are presented in Table 1.

Table 1. Physicochemical properties of seven brands of amoxicillin trihydrate capsules

\begin{tabular}{|c|c|c|c|c|}
\hline Brand & $\begin{array}{c}\text { Weight uniformity } \\
\mathbf{( g )} \\
\text { Mean } \pm \text { SD }\end{array}$ & $\begin{array}{c}\text { Disintegration time } \\
\text { (minutes) } \\
\text { Mean } \pm \text { SD }\end{array}$ & $\begin{array}{c}\text { Dissolution at 60 } \\
\text { minutes (\%) } \\
\text { Mean } \pm \text { SD }\end{array}$ & $\begin{array}{c}\text { Assay (\%) } \\
\text { Mean } \pm \text { SD }\end{array}$ \\
\hline & & & & \\
A1 & $0.597 \pm 0.016$ & $6.363 \pm 0.172$ & $90.956 \pm 0.707$ & $108.970 \pm 0.586$ \\
A2 & $0.600 \pm 0.005$ & $4.630 \pm 0.312$ & $89.471 \pm 1.179$ & $107.390 \pm 1.088$ \\
A3 & $0.622 \pm 0.005$ & $5.210 \pm 0.518$ & $94.906 \pm 0.926$ & $110.436 \pm 0.391$ \\
A4 & $0.571 \pm 0.019$ & $3.863 \pm 0.551$ & $83.684 \pm 1.345$ & $107.729 \pm 0.391$ \\
A5 & $0.587 \pm 0.007$ & $3.153 \pm 0.252$ & $92.238 \pm 0.728$ & $109.082 \pm 0.391$ \\
A6 & $0.636 \pm 0.015$ & $4.473 \pm 0.423$ & $97.967 \pm 0.192$ & $107.390 \pm 0.195$ \\
A7 & $0.593 \pm 0.006$ & $3.517 \pm 0.180$ & $91.651 \pm 0.870$ & $107.842 \pm 0.517$ \\
\hline
\end{tabular}

\section{Uniformity of weight determination}

Weight variation is important to ensure good manufacturing practices (GMP) sustained by the manufacturers and the content uniformity of the formulation $^{22}$. From results (Table 1 ) it was noticed that the uniformity of weight determination for all the brands showed compliance with the BP 2018 specification, as none of the brands deviated by up to $\pm 5.0 \%$ from their mean values. This 
indicates that the factors leading to weight variation were taken in consideration. Factors that affect tablet weight includes tooling of the compression machine, head pressure, machine speed and flow properties of the powder ${ }^{23}$.

\section{Disintegration test}

It was observed that all brands of amoxicillin trihydrate capsules passed BP 2018 specification of disintegration test, as the disintegration time of amoxicillin trihydrate capsules was less than 30 minutes (Table 1).

\section{Dissolution test}

The dissolution test is the measurement of the proportion of drug dissolving in a stated time under standardized conditions in vitro ${ }^{24}$. The importance of the test is to ensure the availability of the drug for absorption and to predict in vivo bioavailability ${ }^{9}$.

The calibration curve was shown in Figure 1, and the resulted regression equation as following:

$\mathrm{Y}=0.0028 \mathrm{x}+0.0092, \mathrm{R}^{2}=0.999998$

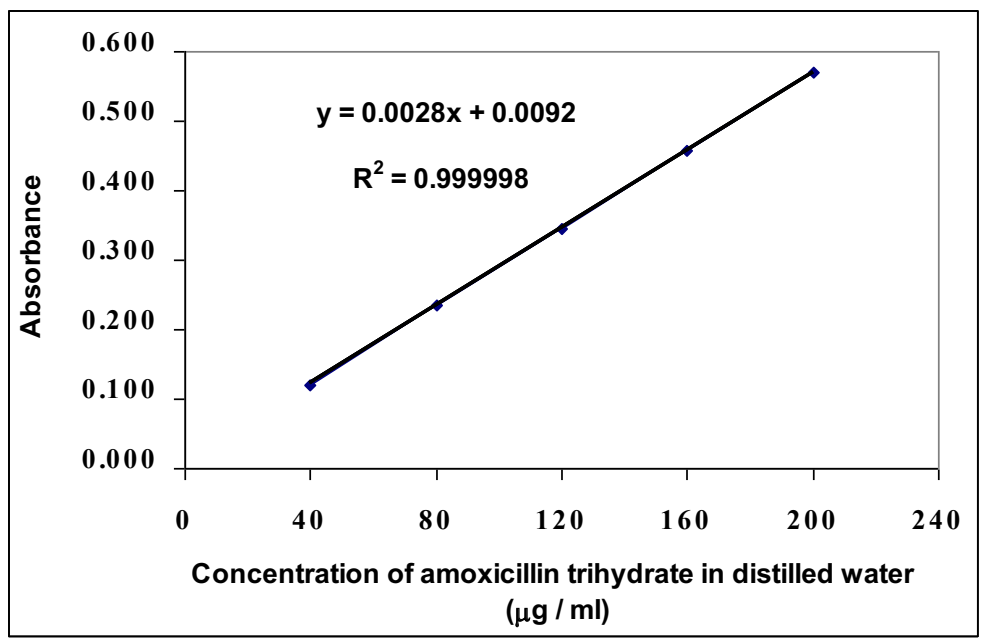

Figure 1: Calibration curve for amoxicillin trihydrate in distilled water.

The USP 41 stipulated that at 60 minutes, all capsules should have released into the dissolution medium an amount not less than $80.0 \%$ of the labeled amount of amoxicillin trihydrate. The percentage mean of the amount released at 60 minutes which are represented in Table 1 showed that all brands passed the dissolution test, that all brands released more than $80.0 \%$ of their content within 60 minutes. 
It was observed that all brands meet pharmacopoeia specification of dissolution test. The results revealed that all brands exhibit good release of the drug to the site of absorption and may have good bioavailability. It is interesting to note that several authors have previously disagreed on the correlation between disintegration time and dissolution time. Some authors mention that disintegration and dissolution times are correlated, while others continue to disagree9. From the results, it was observed that no high range between times of the disintegration of brands, but it was noticed the differences in the dissolution profiles between brands as shown in Figure 2. Dissolution of drugs can be influenced by the physicochemical properties of the drug substance, the dosage form design, the manufacturing process, and the testing conditions ${ }^{25}$. As there are many factors affecting on the dissolution, this gives each product certain dissolution characteristics which varies from brand to another. So it is not surprising to observe variation in vitro dissolution among seven brands amoxicillin trihydrate capsules which were investigated in this study.

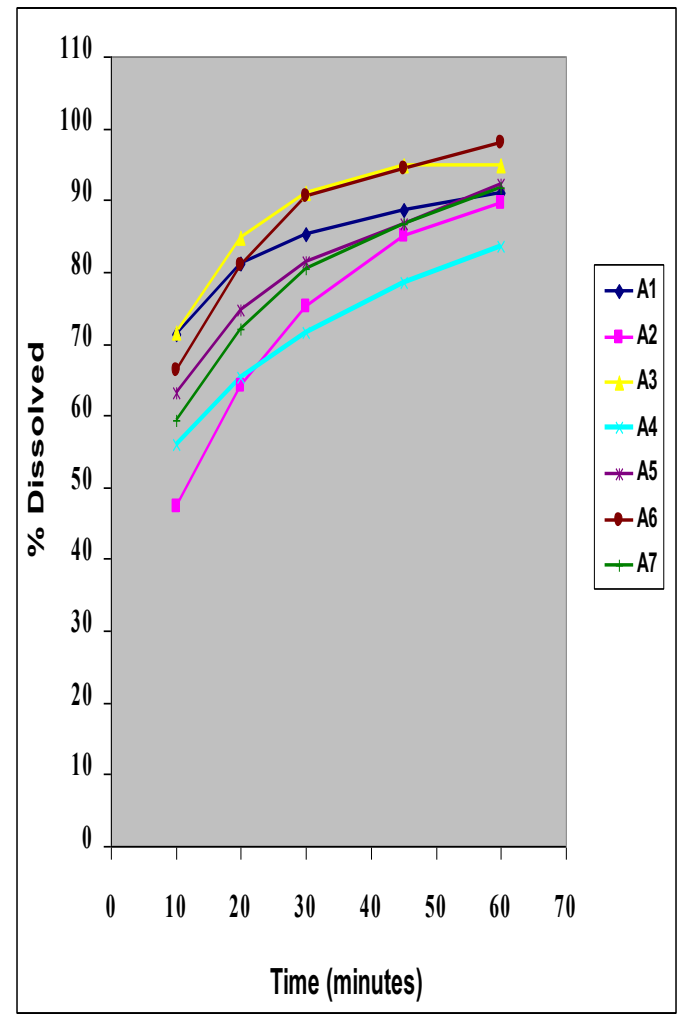

Figure 2: Dissolution profile of the seven different brands of amoxicillin trihydrate capsules in distilled water. 


\section{Analytical method validation}

From the results (Table 2) it was observed that the recoveries percentage of the added pure amoxicillin trihydrate were in the range of (98.506 - 102.593 $\%)$, this indicated excellent accuracies and no interference from excipients was exhibited. SD is less than 2.0 and RSD \% is less than $2.0 \%$, this indicated the high precision of the method.

Table 2. Results of recovery study of amoxicillin trihydrate using Dibbern et al. method

\begin{tabular}{|c|c|c|c|c|c|}
\hline & $\begin{array}{c}\text { Amount of amoxicillin } \\
\text { trihydrate in } \\
\text { formulation }(\mu \mathrm{g})\end{array}$ & $\begin{array}{l}\text { Amount of pure } \\
\text { amoxicillin trihydrate } \\
\text { added }(\mu \mathrm{g})\end{array}$ & $\begin{array}{l}\% \text { Recovery of } \\
\text { pure amoxicillin } \\
\text { trihydrate }\end{array}$ & SD & RSD \% \\
\hline \multirow[t]{3}{*}{$\mathrm{A} 1$} & 20.0 & 10.0 & 99.369 & 0.865 & 0.870 \\
\hline & 20.0 & 20.0 & 101.249 & 0.330 & 0.326 \\
\hline & 20.0 & 40.0 & 100.023 & 0.804 & 0.804 \\
\hline \multirow[t]{3}{*}{ A2 } & 20.0 & 10.0 & 99.952 & 0.158 & 0.158 \\
\hline & 20.0 & 20.0 & 101.756 & 1.116 & 1.096 \\
\hline & 20.0 & 40.0 & 99.577 & 0.000 & 0.000 \\
\hline \multirow[t]{3}{*}{ A3 } & 20.0 & 10.0 & 100.576 & 0.000 & 0.000 \\
\hline & 20.0 & 20.0 & 101.118 & 1.175 & 1.162 \\
\hline & 20.0 & 40.0 & 98.506 & 0.000 & 0.000 \\
\hline \multirow[t]{3}{*}{ A4 } & 20.0 & 10.0 & 100.570 & 0.000 & 0.000 \\
\hline & 20.0 & 20.0 & 102.593 & 1.167 & 1.137 \\
\hline & 20.0 & 40.0 & 99.886 & 0.819 & 0.820 \\
\hline \multirow[t]{3}{*}{ A5 } & 20.0 & 10.0 & 99.136 & 1.842 & 1.858 \\
\hline & 20.0 & 20.0 & 101.054 & 0.000 & 0.000 \\
\hline & 20.0 & 40.0 & 100.786 & 0.000 & 0.000 \\
\hline \multirow[t]{3}{*}{ A6 } & 20.0 & 10.0 & 100.424 & 0.000 & 0.000 \\
\hline & 20.0 & 20.0 & 100.362 & 0.917 & 0.913 \\
\hline & 20.0 & 40.0 & 100.608 & 0.845 & 0.839 \\
\hline \multirow[t]{3}{*}{ A7 } & 20.0 & 10.0 & 101.049 & 0.000 & 0.000 \\
\hline & 20.0 & 20.0 & 101.152 & 1.897 & 1.876 \\
\hline & 20.0 & 40.0 & 99.810 & 0.927 & 0.929 \\
\hline
\end{tabular}

*mean value of three determinations. 
Thus, the Dibbern et $\mathrm{al}^{21}$. method is simple, rapid, no laborious time consuming, inexpensive and no need for high cost instruments. The significant advantage is the possibility of using the method to assay the drug in complex dosage formulation in presence of the excipient without any interferences.

\section{Assay of content of amoxicillin trihydrate}

Assay of pharmaceutical products is a critical quality parameter required to confirm that the labeled amount of drug is available in a given dosage form and failure to meet the standard will result in poor quality medicines. Inadequate amounts of active pharmaceutical ingredient (API) will result in under-dosed medication, leading to poor treatment outcomes while excessive amounts of API cause over-dosage of medication, leading to increased adverse drug reactions and treatment failure ${ }^{26}$.

The results showed that brands (A1, A2, A4, A5, A6, and A7) had values range (107.390-109.082\% w/w), thus it lies within BP 2018 acceptable range (92.5-110.0\% w/w), while brand (A3) had value $110.436 \% \mathrm{w} / \mathrm{w}$, thus not lies in BP 2018 acceptance range (Table 1 ).

It was observed that one of seven brands of amoxicillin trihydrate capsules (A3) failed to be within BP 2018 specification range of (92.5-110.0\% w/w). This revealed that there is a problem in manufacturing of failed brands, while there is good manufacturing for accepted brands. 


\section{REFERENCES}

1. Abraham W, Abuye H, Kebede S, Suleman S. In Vitro Comparative Quality Assessment of Different Brands of Doxycycline Hyclate Finished Dosage Forms: Capsule and Tablet in Jimma Town, South-West Ethiopia. Hindawi: Advances in Pharmacological and Pharmaceutical Sciences. 2021:10 pages.

2. Kassaye L, Genete G. Evaluation and comparison of in-vitro dissolution profiles for different brands of amoxicillin capsules. African Health Sciences. 2013; 13(2): 369-375.

3. Thambavita D, Jayathilake CM, Sandamali KDD, Galappatthy P, Jayakody RL. In Vitro Dissolution Testing to Assess Pharmaceutical Equivalence of Selected Amoxicillin Products Available in Sri Lanka: A Post-Marketing Study. Dissolution Technologies. 2019: 56-61.

4. Hasin F, Hossain MdM, Ghosh MK, Paul S, Rahman M, Ahmad MdF. Pharmaceutical Quality Evaluation of Cefuroxime Axetil Tablets Available in Drug Market of BANGLADESH. World Journal of Pharmacy and Pharmaceutical Sciences. 2017; 7(1): 1589-1599.

5. Banker GS. Drug Products: Their role in the treatment of disease, their quality and their status and future as drug-delivery systems. Modern pharmaceutics; New York: Marcel Dekker, Inc.; 2002. 1-21.

6. World Health Organization and Cairo university, Guidelines for good manufacturing practice of pharmaceuticals in Egypt, Faculty of pharmacy, Cairo University, Central administration of pharmacy, WHO, Cairo, 19941

7. Odeniyi MA, Adegoke OA, Adereti RB, Odeku OA, Itiola OA. Comparative analysis of eight brands of sulfadoxinepyrimethamine tablets. Tropical Journal of Pharmaceutical Research. 2003; 2(1): 161-167.

8. El Attug M, Ammar A, Ben Ahmed A, Alborawy H, Mashina A, Al Mug T, et al. Pharmaceutical Assessment Of Five Different Generic Brands of Prednisolone Tablets In Libyan Market. World Journal of Pharmaceutical Research. 2015; 4(10): 1-18.

9. Nwodo N, Uzochukwu I, Omeje EO. Quality control assessment and the possibility of interchangeability between multisourced norfloxacin tablets marketed in Nigeria. Scientific Research and Essay. 2007; 2(8): 348-352.

10. Crawford P, Feely M, Guberman A, Krämer G. Are there potential problems with generic substitution of antiepileptic drugs? A review of issues. Seizure. 2006; 15: 165-176.

11. Shargel L, Andrew BC. Yu. Applied biopharmaceutics \& pharmacokinetics. $7^{\text {th }}$ edition. New York: McGraw-Hill; 2016.

12. Shah V. Dissolution: a quality control test vs a bioequivalent test. Dissolution Technol. 2001; 8(4): 1-2.

13. Hassali MA, Thambyappa J, Saleem F, Haq N, Aljadhey V. Generic substitution in Malaysia: recommendations from a systematic review. Journal of Applied Pharmaceutical Science. 2012; 2(8): 159-164.

14. Sufian MA, Uddin MS, Islam MT, Zahan T, Hossain K, Uddin GMS, et al. Quality control parameters of parenteral pharmaceuticals based on pharmacopoeias. Indo American Journal of Pharmaceutical Sciences. 2016; 3(12): 1624-1638.

15. Uddin MdS, Al Mamun A, Hossain MdS, Asaduzzaman Md, Sarwar MdS, Rashid M, et al. In vitro quality evaluation of leading brands of ciprofloxacin tablets available in Bangladesh. BMC Research Notes. 2017; 10(185): 2-9. 
16. Cockburn R, Newton PN, Agyarko EK, Akunyili D, White NJ. The global threat of counterfeit drugs: why industry and governments must communicate the dangers. Plos Med. 20o5; 2(4):100.

17. Anonymous. Counterfeit medications. https://en.wikipedia.org/wiki/Counterfeit_medications.

18. Glass BD. Counterfeit drugs and medical devices in developing countries. Dove Press Journal: Research and Reports in Tropical Medicine. 2014; 5: 11-22

19. Issa MM, Nejem R, Al- Kholy M, El-Abadla N, Helles RS, Saleh AA. An indirect atomic absorption spectrometric determination of ciprofloxacin, amoxicillin and diclofenac sodium in pharmaceutical formulations. Journal of the Serbian Chemical Society. 2oo8; 73 (5): 569-576.

20. Basavaiah K, Nagegowda P, Somashekar BC, Ramakrishna V. Spectrophotometric and titrimetric determination of ciprofloxacin based on reaction with cerium (IV) sulphate. Science Asia. 2006; 32: 403-409.

21. Dibbern HW, Müller RM, Wirbitzki E. UV and IR spectra: Pharmaceutical substances (UV and IR) and pharmaceutical and cosmetic excipients (IR), Germany: Editio Cantor Verlag; 2002.

22. Hegazy N, Abuwked E, Musallam A, El-Shanti A, Emghary M, AbdAlaziz I, et al. Comparative in vitro evaluation of various commercial brands of valsartan tablets marketed in Gaza Strip. Medcare Science Publisher, International Journal of Pharma Medicine. 2021; 1: 5 Pages. 23. Abbirami V, Sainithya P, Shobana A, Devi DR, Hari BNV. A Review on In-vitro Bioequivalence Studies and its Methodologies. International Journal of ChemTech Research. 2013; 5(5): 2295-2302.

24. Lachman L, Liberman HA, Kanig JL. The Theory and Practice of Industrial Pharmacy.; $3^{\text {rd }}$ edition. Bombay: Varghese publication; 2008. 300-804.

25. Kassahun H, Asres K, Ashenef A. In vitro quality evaluation of metformin hydrochloride tablets marketed in Addis Ababa. Bangladesh J. Sci. Ind. Res. 2019; 54(2): 169-176.

26. Abebe S, Ketema G, Kassahun H. In vitro Comparative Quality Assessment of Different Brands of Furosemide Tablets Marketed in Northwest Ethiopia. Dove Press journal: Drug Design, Development and Therapy. 2020; 14: 5119-5128. 